\title{
SUSTAINABILITY - A NEW DIMENSION IN INFORMATION SYSTEMS EVALUATION
}

\author{
Wojciech Piotrowicz, Saïd Business School, University of Oxford, UK \\ Wojciech.Piotrowicz@sbs.ox.ac.uk \\ Richard Cuthbertson, Saïd Business School, University of Oxford, UK \\ Richard.Cuthbertson@sbs.ox.ac.uk
}

Reference:

Piotrowicz W, Cuthbertson R, (2009). Sustainability - a new dimension in information systems evaluation. Journal of Enterprise Information Management 22(5) 492-503

This paper received Outstanding Paper Award 2010, Emerald Literati Network Awards for Excellence

\begin{abstract}
The paper introduces new dimensions of Information Systems evaluation. Sustainability issues have increasing importance and their influence is compared with the Internet revolution. Customers, policymakers and business partners increasingly require the monitoring and reporting of the impact of an organisation on sustainability. However, traditional IS evaluation approaches are not able to capture the impact of IT/IS on sustainability, especially in relation to social and environmental dimensions. In order to stimulate discussion and research, the authors propose a framework that was originally developed to focus on supply chain practices. The framework is built upon three dimensions: economic, social and environmental, which are divided further into three sub-dimensions. It can be used as a staring point to develop a framework for sustainability-oriented IS evaluation. In the paper the sustainability drivers are presented, and the problems related to IT/IS evaluation are discussed using selected examples from IT/IS applications in supply chains. IT/IS solutions used in supply chains are perceived as having both positive and negative effects on sustainability. Moreover some business models supported by IT/IS that are perceived as positive for the supply chain processes, could be considered negative after taking into consideration their external effects on sustainability.
\end{abstract}

Sustainability and its new dimensions create new challenges for Information Systems evaluation. Companies require frameworks and tools that can help to measure and evaluate the organisational impact on sustainability, to create a sustainability-oriented IS evaluation. The researcher's role is to answer such needs and concentrate on this emerging research topic.

Keywords: supply chain, logistics, IS evaluation, sustainability, best practice, BestLog project

This paper is based on the paper submitted by the authors for the European and Mediterranean Conference on Information Systems EMCIS 2008. For more details about EMCIS, please visit www.emcis.org 
This paper discusses the emerging issue of Information Systems evaluation with respect to sustainability. Although it is derived from practical examples of supply chain information systems, this paper is theoretical and conceptual; it aims to stimulate discussion and define a research agenda for the topic presented. Sustainable development is a new area that has started to be incorporated into mainstream operations management, logistics and information systems. Research related to sustainability is still at an early stage but is increasing rapidly (Linton, et al. 2007). However, the current level of knowledge relating to the environmental impact of e-business and ICT is limited (Yi, et al. 2007), while Information Technology is perceived as having both negative and positive influences on the environment (EC 2006c). Sustainability, according to the definition of the European Commission, includes not only economic, but also social and environmental aspects (EC 2007). This paper is using example of IT/IS applications dedicated to the supply chain (SC) as a basis to discuss the emerging trend of sustainability-oriented Information Systems evaluation. One of the major focuses of sustainability is on supply chains, as transport results in negative social and environmental impacts, such as congestion, road accidents and pollution. From individuals, organisations, and recently from governments, through regulation, there is pressure to reduce the negative impact of transport. One of the enablers that could improve supply chains is IT/IS. To fulfil promises given to customers, that a company will "green" its supply chain, as well as to achieve national and $\mathrm{EU}$ targets to reduce $\mathrm{CO}_{2}$ emissions, organisations implement various solutions, including IT/IS applications. This situation creates a new dimension in IT/IS investments evaluation. This evaluation is going to be extended and will incorporate other impact categories beyond the traditional commercial aspects. There are already some recommendations for policy makers to extend ICT evaluation into environmental factors (Hambreaeus-Bjorling 2006, Pamlin, et al. 2004) and the academic community needs to respond to the requirements of stakeholders to provide IT/IS evaluation frameworks that consider sustainability. This paper provides a framework for the analysis of supply chain and logistics practices that is proposed as a starting point for the development of sustainabilityoriented IS evaluation. In the paper, current drivers of sustainability are presented. The role of IT/IS in SC and their relationships to sustainability are overviewed, followed by a presentation of the framework for SC practices evaluation that was developed during the BestLog project. Shortages of current IS evaluation approaches are identified and future research directions proposed.

\section{METHODOLOGY}

This theoretical paper aims to discuss sustainability issues within an Information Systems evaluation concept. The paper does not aim to review the interdisciplinary literature related to sustainability, but initiates discussion on sustainability-oriented IS evaluation. While the paper is largely theoretical, it makes use of the results of empirical work from the EU financed BestLog project, which provides a framework for evaluating sustainable practices in Supply Chains. This will illustrate the concept of sustainability and its evaluation dimensions, which can then be assessed in terms of its relevance to IS evaluation. To create the framework, literature reviews, analysis of existing case studies, as well as the results of 32 specific case studies were used. Even though the framework was built to assess a whole range of supply chain initiatives, it can also be used as a starting point for the evaluation of IT/ISrelated practices. The authors believe that this paper will stimulate research related to sustainability-oriented IS evaluation answering the emerging needs of policy makers, customers and businesses. The proposed framework can be tested, further developed and adjusted to evaluate IT/IS investments and system applications to determine their impact on sustainability. To illustrate the emerging need for sustainability-oriented IS evaluation, the latest articles and company documents were reviewed, some examples selected and these are presented in the paper. The limitation of the approach presented is that the paper is primarily 
conceptual at this stage, as the presented framework was originally developed to evaluate a wide range of supply chain practices, not exclusively IT/IS implementations.

\section{SUSTAINABILITY DRIVERS AND SUSTAINABLE SUPPLY CHAIN}

Sustainability is one of the latest "buzzwords" among politicians and businesses. Sustainability is sometimes compared with the Internet revolution given its wide-ranging impact on businesses. Sustainability is in many cases, but not correctly, associated with the environmental aspects only, while corporate social responsibility is more often perceived as primarily social-oriented. Additional confusion is created by the various social and environmental-focused initiatives related to climate change or fair trade (see also review of sustainability terms (Glavic, et al. 2007)). Customers and policy makers require actions from businesses to include sustainability into their overall business agenda, despite a lack of common understanding on what sustainability really means. The European Union defines sustainable development as "progress that integrates immediate and longer-term needs, local and global needs, and regards social, economic and environmental needs as inseparable and interdependent components of human progress" (EC 2007), clearly identifying the social, economic and environmental dimensions, which also relate to transport and logistics (EC 2006a, b). To fulfil the needs of policy makers and customers, companies are trying to respond. However, it is not enough just to talk about being sustainable, companies must provide evidence, such as confirmation that they are reducing $\mathrm{CO}_{2}$ emission, and participating in the "greening" of transport. Customers and business partners alike may demand such information. Transport is one of the main areas where improvements are expected. There is a variety of potential solutions, such as car-free zones, through bio-diesels, to co-modal transport solutions. IT/IS is perceived as a vital element that will improve information sharing and coordination, and so result in supply chain improvement. At the European level, working documents list ICT as an enabler that could improve transport efficiency and effectiveness (EC 2006a, b). This new situation creates new problems concerning the evaluation of supply chain activities, including IT/IS solutions. A lack of commonly accepted definitions of sustainability and existing standards makes it problematic to design, or modify evaluation approaches to reflect the sustainability aspects. Sustainability issues cannot be captured by traditional performance measurement and evaluation methods that are focussed on organisational and economic performance (BestLog 2007). As a result sustainability measurement is perceived as a difficult task (IEE 2003), while the impact of ICT on the environment is not well understood (Pedersen, et al. 2005). A sustainability-oriented IS evaluation is likely to emerge from the implementation of IT/IS in supply chains, due to the importance of information systems and their usage in supply chain, but it is likely that this will eventually be extended to all IT/IS investments.

Apart from the impact of implementing Information Systems, there is also the direct impact of IT/IS on sustainability relating to the materials used to build the hardware, energy use, toxic substances, product durability, use of renewable resources and hardware recycling (IEE 2003). The largest part of the energy used through IT products lifecycle is during its usage (Hambreaeus-Bjorling 2006, Pedersen, et al. 2005). To produce a desktop computer with a 17 inch monitor the equivalent of $260 \mathrm{~kg}$ of fossil fuel is required and it uses 1.3 time more energy per year than a fridge (Williams 2004), and when disposed, electronic equipment damages the environment. Such costs should also be considered in any assessment of IT/IS investments.

Some companies from the IT/IS sector have already started to respond to new demand for sustainable business and have decided to be proactive in tackling sustainability issues. It is possible to see that this represents a major change in companies' approaches, as the IT industry was perceived to be not greatly aware of sustainability needs just a few years ago (Pamlin, et al. 2004). 
Some organisations, including major players in the IT/IS industry, have started to seriously consider sustainability issues. This section does not aim to provide a comprehensive and structured review, but gives some illustrations of this increasing trend showing that IT/IS leaders have incorporated sustainability aspects into their business. Some of introduced initiatives have been voluntary, including using sustainability for marketing purposes, while other changes have been compulsorily driven by government policy and regulations. For example, environmental aspects relating to hardware recycling are regulated by the WEEE (Waste Electrical and Electronic Equipment) and RoHS (Restriction of the use of certain Hazardous Substances in electrical and electronic equipment) directives and impact all electronic good manufacturers and distributors operating within the European Union. The European Commission have defined the level of electronic goods that should be recycled (ewaste recycling). This has resulted in the creation of reverse supply chains in which computers and other hardware are collected and "de-manufactured". Hardware manufacturers have also joined the Climate Savers Computing Initiative, defining minimum percentage efficiency and "Energy Star" requirements for new computers. The initiative aims to reduce the $\mathrm{CO}_{2}$ emission from computers by 2010, at the same time as reducing energy costs, through a $50 \%$ reduction in annual computer power consumption (Climate Savers 2007). Apart from joining this Initiative, organisations such as Intel have also reduced their own carbon footprint (Intel 2007) through other voluntary programmes. Sun promotes its solutions using a sustainable computing concept that aims to be more sustainable compared to current client/server models (Sun 2007). A major software provider, SAP, has introduced applications that support emission management, via emission monitoring, measurement, modelling and comparison with regulations (SAP 2006). Another software solution is dedicated to support environment, health and safety compliance (SAP 2007). All these initiatives show that the sustainability agenda is moving to all businesses, including the IT/IS industry.

\section{IT/IS AND SUSTAINABILITY IN SUPPLY CHAINS}

Information Technology is perceived as an integral part of a supply chain (Byrd, et al. 2003). IT in supply chain covers six main areas: strategic planning, virtual enterprise, e-commerce, infrastructure, knowledge, IT management and finally the implementation of IT in Supply Chain Management (Gunasekaran, et al. 2004a). (Vickery, et al. 2003) categorised integrative information technologies into three groups:

- Computerized productions systems (MRP, MRPII, ERP) - that integrate manufacturing activities, especially through joint production planning, tracking, scheduling and ordering from suppliers.

- Integrated information systems - that provide the ability to transmit and share information within the organisation, both horizontally and vertically.

- Integrated electronic data interchange (EDI) - that allows automating electronic documents to flow within and between organisations. These links with customers and suppliers create vertical integration.

(Hilty, et al. 2006) identified five key areas related to environmental sustainability in freight transport: Supply Chain Management (SCM) that increases efficiency by applying ICT, teleshopping, virtual goods, Intelligent Transport Systems and production process management. Relationships between ICT and transport and their links with sustainability are complex (Black, et al. 2006). There are some conclusions that ICT in isolation has a limited impact on transport. Other factors, such as energy prices and policies could stabilise transport growth using current ICT, according to most modelling scenarios, by increasing transport intensity (Hilty, et al. 2006). However, other authors claim that ICT has a large potential in reducing the negative environmental impact of transport (Pedersen, et al. 2005) and ICT is perceived as a tool that could change transport, by increasing its efficiency (HambreaeusBjorling 2006). Some business strategies (such as Just-In-Time) supported by IT/IS increase 
delivery distance, frequency and smaller loads (Black, et al. 2006), so ICT might have a net negative effect on freight transport volumes (Erdmann, et al. 2003). On the other hand, the use of Internet freight exchanges could improve vehicle fill and backloads (Davies, et al. 2007). These mixed arguments suggest that IT technologies used to support supply chain management can have different impacts on sustainability, depending on the context and content of the IT/IS system employed, so further analysis of IT/IS impact on supply chain, and finally on sustainability, is required. In the following section, a framework that could help to assess the IT/IS impact on sustainability in supply chains is proposed as a starting point to develop sustainability-oriented IS evaluation.

\section{6}

FRAMEWORK FOR EVALUATING SUPPLY CHAIN PRACTICES

The framework, selected to illustrate the sustainability concept, is presented in this section. It was developed as part of the BestLog - Best Practices in Logistics project (www.bestlog.org). BestLog was initiated by the European Commission and aims to improve logistics/supply chain practice and education, as well as to reduce differences across Europe. The framework includes social, economic and environmental dimensions for evaluation. In addition to the framework a methodology was also developed to assess supply chain practices. The framework was created based on a review of the literature from operations management, operational research and logistics disciplines and existing literature related to supply chain measurement and evaluation (see: BestLog 2007), supported by an analysis of existing case studies and two-stage fieldwork completed across Europe, covering various industries and supply chain areas (32 case studies were completed). The framework was designed to be as generic as possible in order to apply to a wide range of SC areas and industries. The presented framework was not developed to evaluate exclusively IT/IS implementations, however among the initiatives analysed, almost all had an element of IT/IS and two case studies in particular had a clear IT/IS focus - e-procurement system and WEEE directive implementations (see Piotrowicz 2008).

The framework is built upon three main dimensions - social, economic and environmental. Every dimension is divided further into three additional sub-dimensions (figure 1).

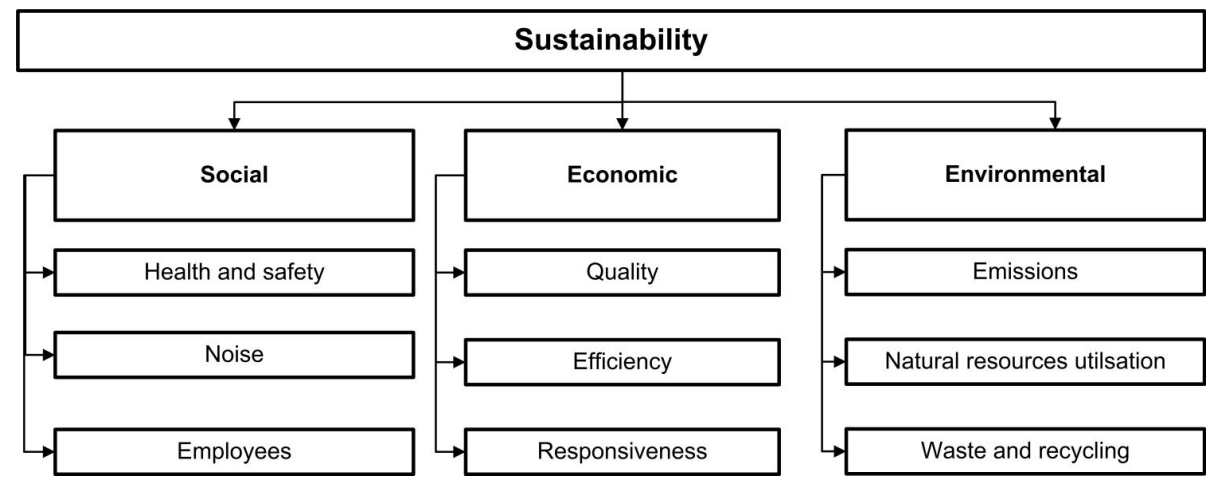

Figure 1. Sustainability dimensions and sub-dimensions

To create a generic and flexible framework, within each dimension various metrics categories can be used to confirm the impact. As there are differences between companies located within various supply chain points and industries, the metrics used are also different. An organisation could use a variety of metrics to confirm their impacts on the dimensions and sub-dimensions (table 1). 


\begin{tabular}{|c|c|c|c|c|c|}
\hline \multicolumn{2}{|l|}{ Social } & \multicolumn{2}{|l|}{ Economic } & \multicolumn{2}{|l|}{ Environmental } \\
\hline Sub-dimension & $\begin{array}{l}\text { Impacts } \\
\text { (examples) }\end{array}$ & $\begin{array}{l}\text { Sub- } \\
\text { dimension }\end{array}$ & $\begin{array}{l}\text { Impacts } \\
\text { (examples) }\end{array}$ & Sub-dimension & $\begin{array}{l}\text { Impacts } \\
\text { (examples) }\end{array}$ \\
\hline $\begin{array}{l}\text { Health and } \\
\text { safety }\end{array}$ & $\begin{array}{l}\text { Toxic, hazardous } \\
\text { emissions } \\
\text { Accidents } \\
\text { Working } \\
\text { conditions }\end{array}$ & Quality & $\begin{array}{l}\text { Quality of products and } \\
\text { services } \\
\text { Customer service level } \\
\text { Availability }\end{array}$ & Emissions & $\begin{array}{l}\mathrm{CO}_{2} \text { emission } \\
\text { Other pollutants emissions }\end{array}$ \\
\hline Employees & $\begin{array}{l}\text { Employment } \\
\text { Training } \\
\text { Job security }\end{array}$ & Efficiency & $\begin{array}{l}\text { Utilisation } \\
\text { Productivity } \\
\text { Cost reduction }\end{array}$ & $\begin{array}{l}\text { Natural } \\
\text { resources } \\
\text { utilisation }\end{array}$ & $\begin{array}{l}\text { Fuel consumption } \\
\text { Water consumption } \\
\text { Land use } \\
\text { Energy consumption }\end{array}$ \\
\hline Noise & $\begin{array}{l}\text { Volume } \\
\text { Timing and } \\
\text { location }\end{array}$ & $\begin{array}{l}\text { Responsive } \\
\text { ness }\end{array}$ & $\begin{array}{l}\text { Response to customer } \\
\text { needs } \\
\text { Response to market } \\
\text { changes } \\
\text { Flexibility }\end{array}$ & $\begin{array}{l}\text { Waste and } \\
\text { recycling }\end{array}$ & $\begin{array}{l}\text { Waste reduction } \\
\% \text { of materials. products } \\
\text { recycled } \\
\text { Bio-degradable materials } \\
\text { used }\end{array}$ \\
\hline
\end{tabular}

Table 1 .

Metrics for assessing supply chain practice impact on sustainability

Examples of the impacts, and their related metrics, are a combination of qualitative/quantitative (Chan, et al. 2003, Shepherd, et al. 2006) and financial/non-financial measures (Gunasekaran, et al. 2004b, Gunasekaran, et al. 2001). In supply chain, the most developed and commonly used metrics are economic, while social and environmental issues are largely ignored in SC performance measurement (see Cuthbertson, et al. 2008).

In evaluating sustainable SC practices, the authors propose to look beyond economic measures. These are grouped into three sub-categories - quality, efficiency and responsiveness. The economic benefits evaluation is already well developed so it will not be explored further in this paper.

The second dimension of evaluation is related to social aspects. This considers how the practice, such as IT/IS, impacts social issues. The social dimension includes three subdimensions: health and safety, employees and noise. At first glance, the relation of IT/IS systems in SC to these dimensions appears slight. However, with respect to health and safety, new automated warehouses could reduce the risk of accidents, fleet monitoring systems could increase safe driving, the monitoring of dangerous cargo transport might reduce the rate of major incidents; on the other hand, there are emissions from IT hardware that might have a negative impact on health, or the application of some IT solutions may increase transport frequency and distance travelled by vehicles and so increases the risk of road accidents and congestion. In relation to employment, IT/IS might reduce the number of staff required, but could also provide new skills to employees. Some IT/IS (such as e-procurement) might make it more difficult for SME's to access buyers, but at the same time e-procurement increases supplier control and may help exclude companies that do not fulfil environmental or social requirements. In the case of noise emission, better delivery planning and scheduling systems might reduce noise emission when the delivery is in an urban area.

The environmental dimension is similar to the social as there is the direct impact of using IT/IS, as well as the indirect effects of the IS/IT application. The direct effects include new IT hardware replacing old hardware that ends up as landfill, resulting in toxic emissions into the environment. To create and transport IT hardware, fossil fuel is used and $\mathrm{CO}_{2}$ emitted. When in use, IT/IS requires energy, which in the case of energy from the fossil fuels will result in further $\mathrm{CO}_{2}$ emission. As with the social dimension, the indirect impacts can be both negative and positive. Better scheduling systems reduce the distances vehicles are required to travel, so fuel consumption can be reduced. Centralised automated warehouses might increase transport distance and associated $\mathrm{CO}_{2}$ emission. Automated warehousing, zero-inventory approaches, supported by IT/IS applications could reduce requirements for land use, but also may result in the abandonment of existing warehouses that do not fulfil new technical parameters. The monitoring of $\mathrm{CO}_{2}$ emission (and other greenhouse gases) is increasingly important as 
companies start to evaluate their "carbon footprint", so both the direct and indirect impacts of IT/IS should be measured. However current IT/IS evaluation frameworks and approaches do not sufficiently cover sustainability issues, especially the environmental and social aspects, current evaluation approaches are also focused mainly on the impact within the organisation and its immediate surrounding, not on the extended external impact.

\section{CONCLUSION - SHORTCOMINGS OF CURRENT IS EVALUATION APPROACHES AND RESEARCH AGENDA}

Although IS evaluation is already a complex issue (Irani 2002) and companies have difficulties in determining the indirect costs of IT/IS implementation (Love, et al. 2006), sustainability adds even more complexity. Current IS evaluation approaches concentrate mainly on economic impacts. However, a truly sustainable evaluation must include an assessment of the social and environmental impacts. This is further complicated for the IT/IS industry by the distinction between direct and indirect effects. For example, the employment of information systems generally has a negative impact on sustainability due to its necessary use of resources, but the impact of those systems on another industry, such as in the case of supply chains, may have a beneficial effect on sustainability by saving resources. While the IT/IS sector might promote energy efficient hardware and software solutions, the greater environmental and social impacts may lie in the application of these solutions - whether positive or negative overall. It is possible to see from the few examples discussed in this paper that the evaluation of sustainability is not an easy task, especially in relation to IT/IS and its usage, but it will develop and may significantly change the perception of IT/IS solutions among stakeholders groups.

In detail, through IT/IS implementation, new social and environmental, as well as economic, impacts should be recognised. For example, the addition of costs related to equipment disposal and transport to "de-manufacturing" facilities is required. Also, the inclusion of environmental and social costs in the total implementation costs might be calculated in order to determine the external costs of IT/IS implementation, as there is currently a lack of integration between IT/IS usage and its impact on the environment. Even where environmental benefits occur, they are not generally recognised. While some authors, such as (Yi, et al. 2007) propose to identify e-business and ICT impacts on the environment, and related indicators, the authors stress the need for a sustainable approach that considers all three dimensions: social, economic and environmental, as well as direct and indirect effects, both within organisation and beyond its boundaries. The proposed framework developed during the BestLog project, provides a starting point to develop sustainability-oriented IT/IS evaluation that answers the needs of industry, society and policy makers.

The future IS research agenda related to sustainability should consider:

- The overall impacts of IT/IS on sustainability and how to measure this.

- The social and environmental external costs of IT/IS usage.

- The inclusion of sustainability issues within pre-investment IT/IS planning.

- The design of applications to monitor sustainability performance.

- The impact of IT/IS on the supply chain, and other industries, and the implications for sustainability.

- Analysis of IT/IS infrastructure, applications design, and their usage in regards to their impact on sustainability.

- Analysis of IT/IS driven business models and their impact on sustainability.

- Impact of outsourcing and off shoring on sustainability 
- Cooperation between business managers and policy makers regarding the requirements for assessing the social, environmental and economic impacts of IT/IS.

- An analysis of responses to situations where existing applications currently accepted as beneficial might be perceived as negative when including sustainability issues, and the implications for business model redesign.

\section{References}

BestLog 2007. 'Existing methods of benchmarking'. Best Practices in Logistics (BestLog) project Available at:

http://www.bestlog.org/typo3conf/ext/alternet_securelink/pushFile.php?cuid=560\&file=filead min\%2Fbestlog\%2FbestLog_WP4_D4.1.pdf. Access date: 18.10.2007.

Black, W. and van Geenhuizen, M. 2006. 'ICT innovation and sustainability of the transport sector'. European Journal of Transport and Infrastructure Research, 6(1): 39-60.

Byrd, T.A. and Davidson, N.W. 2003. 'Examining possible antecedents of IT impact on the supply chain and its effect on firm performance'. Information and Management, 41(2): 243255.

Chan, F.T.S., Qi, H.J., Chan, H.K., Lau, H.C.W. and Ip, R.W.L. 2003. 'A conceptual model of performance measurement for supply chains'. Management Decision, 41(7): 635-642.

Climate Savers 2007. 'What is the Initiative? And what are its Objectives?' Climate Savers Computing Initiative Available at: www.climatesaverscomputing.org. Access date:

24.11.2007.

Cuthbertson, R. and Piotrowicz, W. 2008. 'Supply chain best practices - identification and categorisation of measures and benefits'. International Journal of Productivity and Performance Management, 57(5): 389-404

Davies, I., Mason, R. and Lalwani, C. 2007. 'Assessing the impact of ICT on UK general haulage companies'. International Journal of Production Economics, 106(1): 12-27.

EC 2006a. 'Commission staff working document: Freight transport logistics in Europe - the key to sustainable mobility. Appendix: Summary of the impact assessment - points for reflection'. Commission of the European Communities Available at: http://eurlex.europa.eu/LexUriServ/LexUriServ.do?uri=CELEX:52006SC0818:EN:HTML. Access date: 10.02 .2007 .

EC 2006b. 'Commission staff working document: Freight transport logistics in Europe - the key to sustainable mobility. Impact Assessment'. Commission of the European Communities Available at:

http://ec.europa.eu/transport/logistics/overview/doc/2006_06_28_communication_en.pdf. Access date: 10.02.2007.

EC 2006c. 'Information and Communication Technologies for Environmental Sustainability and Growth. Workshop on energy efficiency.' Available at: 
http://ec.europa.eu/information_society/activities/sustainable_growth/docs/ee_report_draft.pd f. Access date: 14.12.2007.

EC 2007. 'Sustainable Development'. European Commission Available at: http://ec.europa.eu/environment/eussd/ Access date: 01.09.2007.

Erdmann, L. and Wurtenberger, F. 2003. 'The future impact of ICT on environmental sustainability. First interim report'. Institute for Prospective Technological Studies (IPTS) Available at: http://susproc.jrc.es/docs/waterdocs/Interim_report_1_final.pdf. Access date: 20.12.2007.

Glavic, P. and Lukman, R. 2007. 'Review of sustainability terms and their definitions'. Journal of Cleaner Production, 15(18): 1875-1885.

Gunasekaran, A. and Ngai, E.W.T. 2004a. 'Information systems in supply chain integration and management'. European Journal of Operational Research, 159(2): 269-295.

Gunasekaran, A., Patel, C. and McGaughey, R.E. 2004b. 'A framework for supply chain performance measurement'. International Journal of Production Economics, 87(3): 333-347.

Gunasekaran, A., Patel, C. and Tirtiroglu, E. 2001. 'Performance measures and metrics in a supply chain environment'. International Journal of Operations \& Production Management, 21(1-2): 71-87.

Hambreaeus-Bjorling, Y. 2006. 'An environmentally appropriate information society in 2020! - a report by the IT Policy Strategy Group'. IT Policy Strategy Group Available at: http://www.sweden.gov.se/download/31b2d300.pdf. Access date: 05.12.2007.

Hilty, L.M., Arnfalk, P., Erdmann, L., Goodman, J., Lehmann, M. and Wager, P.A. 2006. 'The relevance of information and communication technologies for environmental sustainability - A prospective simulation study'. Environmental Modelling \& Software, 21(11): 1618-1629.

IEE 2003. 'Developing Sustainability with the Information Technology Industry, An Energy Environmental Fact Sheet provided by the IEE'. The Institution of Electrical Engineers(IEE) Available at: http://www.theiet.org/factfiles/energy/itenvironment.cfm. Access date: 10.10.2007.

Intel 2007. 'Advancing Global Sustainability Through Technology, White Paper, Ecotechnology innovation'. Intel Available at: www.intel.com/technology/docs/whitepaper_sustainability.pdf. Access date: 25.10.2007.

Irani, Z. 2002. 'Information systems evaluation: navigating through the problem domain'. Information \& Management, 40(1): 11-24.

Linton, J.D., Klassen, R. and Jayaraman, V. 2007. 'Sustainable supply chains: An introduction'. Journal of Operations Management, 25(6): 1075-1082. 
Love, P.E.D., Irani, Z., Ghoneim, A. and Themistocleous, M. 2006. 'An exploratory study of indirect ICT costs using the structured case method'. International Journal of Information Management, 26(2): 167-177.

Pamlin, D. and Thorslund, E. 2004. 'IT and sustainable development - a central issue for the future.' Forum IT-Miljo Available at: http://www.wwf.se/source.php?id=1121817. Access date: 27.10 .2007 .

Pedersen, T., Jorgensen, M., Falch, M., Jorgensen, U. and Willum, O. 2005. 'Green technology foresight about environmentally friendly products and materials. Challenges from nanotechnology, biotechnology and ICT.' Available at: http://www.frontlinien.dk/eco/050414\%20GTF\%20140405\%20ver4.pdf. Access date: 27.10.2007.

Piotrowicz, W. 2008. 'Designing Closed-loop Supply Chain: Implementation of the WEEE directive in the UK'. The European Retail Digest, 56(12-15).

SAP 2006. 'SAP xApp Emissions Management'. SAP AG Available at: www.sap.com/solutions/xapps/xem/index.epx. Access date: 20.10.2007.

SAP 2007. 'Environmental Compliance Solutions'. SAP AG Available at: www.sap.com/solutions/xapps/xem/index.epx. Access date: 20.10.2007.

Shepherd, C. and Gunter, H. 2006. 'Measuring supply chain: current research and future directions'. Journal of Productivity and Performance Management, 55(3/4): 242-258.

Sun 2007. 'Sustainable Computing, Good for your business, great for our planet.'

Vickery, S.K., Jayaram, J., Droge, C. and Calantone, R. 2003. 'The effects of an integrative supply chain strategy on customer service and financial performance: an analysis of direct versus indirect relationships'. Journal of Operations Management, 21(5): 523-539.

Williams, E. 2004. 'Energy intensity of computer manufacturing: hybrid assessment combining process and economic input-output methods'. Environmental Science \& Technology, 38(22): 6166-6174.

Yi, L. and Thomas, H.R. 2007. 'A review of research on the environmental impact of ebusiness and ICT'. Environment International, 33(6): 841-849. 